\title{
Recurrent Abdominal Neuroendocrine Neoplasm
}

National Cancer Institute

\section{Source}

National Cancer Institute. Recurrent Abdominal Neuroendocrine Neoplasm. NCI

Thesaurus. Code C138183.

The reemergence of an abdominal neuroendocrine neoplasm after a period of remission. 